\title{
Percutaneous CT Guided Vertebral Biopsy: Anatomy and Technical Considerations
}

\author{
Kunal Bharat Gala ${ }^{1} \quad$ Nitin S. Shetty ${ }^{1} \quad$ Amit Kumar Janu ${ }^{2} \quad$ Neeraj Shetty ${ }^{1} \quad$ Suyash S. Kulkarni ${ }^{1}$ \\ ${ }^{1}$ Division of Interventional Radiology, Department of \\ Radiodiagnosis, Tata Memorial Hospital, Mumbai, Maharashtra, \\ India \\ 2Department of Radiodiagnosis, Tata Memorial Hospital, Mumbai, \\ Maharashtra, India

\begin{abstract}
Address for correspondence Suyash S. Kulkarni, DMRD, DNB, Professor and Head, Department of Radiodiagnosis, Tata Memorial Hospital, E. Borges Marg, Parel, Mumbai-400012, Maharashtra, India (e-mail: suyashkulkarni@yahoo.com).
\end{abstract} \\ J Clin Interv Radiol ISVIR 2021;5:150-157.
}

\begin{abstract}
In this review article, the authors discuss the anatomy and technical aspects of CT-guided biopsy of vertebral lesions. CT guidance is highly useful for vertebral biopsies, as the anatomy of the spine is complex and varies widely across the levels. Prebiopsy imaging should be reviewed and later correlated with the final histopathological diagnosis. The majority of the spine biopsies are performed under local anesthesia, except those in critical locations and pediatric age groups. The biopsy sample is sent for histopathological analysis and/or microbiological analysis depending on the

Keywords

- spine biopsy

- percutaneous biopsy

- vertebral lesions indications. It is preferable to use a coaxial system for biopsies, so multiple cores can be obtained with a single needle puncture, thus minimizing the negative yield and complications. Complications after image-guided percutaneous biopsy are rare and can be managed easily.
\end{abstract}

Spinal pathologies pose a major diagnostic challenge on the plain radiographs; however with the advent of cross-sectional imaging like CT, PET-CT and MRI, the diagnostic dilemma have reduced to a large extent and these modern radiological imaging tests have a good predictive value. ${ }^{1,2,3}$ The vertebral column is affected by a variety of disease processes ranging from benign ("touch-me-not") lesions to infective and aggressive neoplastic lesions, which require histopathological diagnosis to initiate appropriate treatment. ${ }^{4}$ Biopsies can be performed either by open or percutaneous image guidance. Percutaneous needle biopsy under image guidance is safe and less invasive and can be performed as a day-care or outpatient procedure. It has also lower morbidity and cost

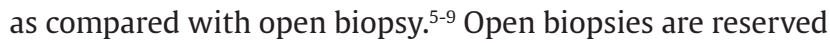
when a percutaneous biopsy is indeterminate on repeated occasions, and there is a high suspicion of malignancy on imaging. Vertebral anatomy is variable at different spinal levels and understanding the anatomical differences can guide the operator on the safe path for biopsy. This review focuses on the relevant anatomy of the spine at various levels, technical aspects of targeting the lesion, and the advantages and limitations of each approach based on the location of the target lesion. Other topics discussed include are patient preparation, image guidance, lesion localization, biopsy techniques, needle selection, and methods to minimize complications.

\section{Normal Spinal Anatomy}

The spinal column consists of 33 vertebrae, which are grouped into different regions as cervical (7 vertebrae), thoracic/dorsal (12 vertebrae), lumbar (5 vertebrae), sacral (5 vertebrae), and coccyx (4 vertebrae). The cross-sectional anatomy of the spine (-Fig. 1) is important to know, as it guides the biopsy approach to avoid injury to vital neurovascular structures. Vertebra consists of anterior arch elements and posterior arch elements. Anterior arch structures consist
DOI https://doi.org/ $10.1055 / \mathrm{s}-0041-1729778$ ISSN 2457-0214
(C) 2021. Indian Society of Vascular and Interventional Radiology. This is an open access article published by Thieme under the terms of the Creative Commons Attribution-NonDerivative-NonCommercial-License, permitting copying and reproduction so long as the original work is given appropriate credit. Contents may not be used for commercial purposes, or adapted, remixed, transformed or built upon. (https://creativecommons.org/licenses/by-nc-nd/4.0/).

Thieme Medical and Scientific Publishers Pvt. Ltd. A-12, 2nd Floor, Sector 2, Noida-201301 UP, India 


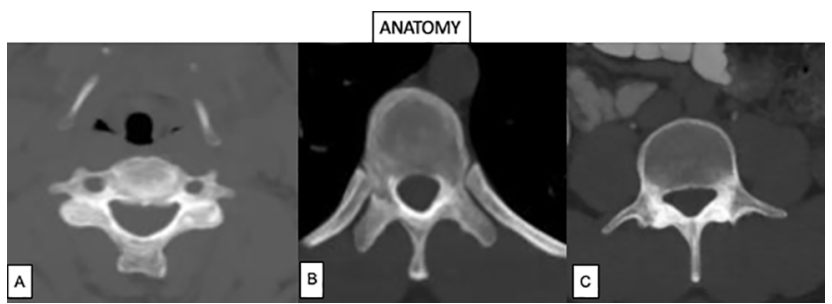

Fig. 1 Axial CT scan sections-Normal anatomy at the level of (A). Cervical vertebra. (B). Thoracic vertebra. (C). Lumbar vertebra. To demonstrate different size of the pedicle and vertebral body.

of the vertebral body and anterior $1 / 3$ rd of the pedicles, while posterior arch structures consist of posterior $2 / 3 \mathrm{rd}$ of the pedicles, lamina and transverse and spinous processes. The spinal cord is within the spinal canal and is segmented by the nerve roots that emerge from it. There are 31 nerve roots in total eight cervical, 12 thoracic, five lumbar, five sacral, and one coccygeal. ${ }^{10,11}$

Anatomical variations exist in the pre and paravertebral spaces at different levels, and it is important to know their boundaries and identify complications such as hematoma. The perivertebral space surrounds the vertebral column and extends from the skull base to the mediastinum in the cervical region. This space is encircled by the deep layer of the deep cervical fascia, which divides the perivertebral space into an anterior prevertebral space and posterior paraspinal space. The prevertebral space extends from the skull base to the coccyx. ${ }^{12}$ In the dorsal region, the paraspinal space gives spinal roots from the intervertebral foramen and divides into dorsal and ventral rami. The sympathetic chain lies in the same fascial plane, just anterior to the intercostal nerve. In the lumbar region, the paravertebral space is limited by the psoas major muscle anterolaterally; the vertebral bodies, the intervertebral discs, and the intervertebral foramen with its contents medially, and the transverse process and the ligaments that are interposed between the adjoining transverse processes posteriorly. Knowledge of this anatomy is important while doing the spine biopsy.

\section{Procedure}

\section{General Principles and Procedural Details}

Before performing the biopsy, procedure preplanning and workup are essential to avoid untoward complications and have a safe procedure.

\section{Patient assessment}

Before performing the biopsy, a thorough clinical evaluation should be performed. Specific attention should be paid toward medical history, prior spinal surgery/instrumentation, spinal trauma, comorbidities, medications, allergies, physical examination findings, and performance status of the patient. One should be aware of the indications and contraindications for the biopsy. The common indications for spinal biopsy include:

- To differentiate between a benign and malignant lesion.

- To determine the nature of a solitary bone lesion with nonspecific findings.
- To evaluate tumor recurrence following surgical or percutaneous therapy.

- Obtain material for culture and sensitivity in case of suspected infections.

The contraindications include:

- Uncorrectable coagulopathy.

- Vascular lesions in the spine.

- Lack of safe access, that is, risk of injury to neurovascular structures.

The laboratory tests for hemoglobin, platelets, and coagulation profile should be obtained. The minimum level of hemoglobin level should be more than $8.0 \mathrm{~g} \%$, platelet counts more than 50,000 per microliter $(\mathrm{mL})$, and international normalized ratio (INR) less than 1.5. The deranged coagulation profile should be corrected before the procedure to avoid potential bleeding complications. ${ }^{13}$ According to the CIRSE ${ }^{14}$ and SIR guidelines, ${ }^{15}$ spine biopsy falls into category two, that is, a moderate risk procedure. According to these guidelines, warfarin and clopidogrel should be stopped 5 days prior to the procedure, but acetylsalicylic acid (aspirin) may be continued. Low-molecular weight heparin (LMWH) should be withheld for one dose prior to the procedure. However, the newer direct oral anticoagulant (DOAC) should be withheld 2 to 3 days prior to the procedure. ${ }^{14}$ If INR is elevated, vitamin $\mathrm{K}$ injection should be considered at 10 to $20 \mathrm{mg} /$ day for 3 days via intravenous, subcutaneously, or intramuscular routes. Platelets should be infused if the manual count is less than $50,000 / \mathrm{mL}$ prior to the procedure. Written informed consent is taken after explaining the risks and benefits of the procedure.

\section{Biopsy planning}

All available imaging should be reviewed prior to the procedure to decide patient position and biopsy approach. Usually, lesions in the thoracic or lumbar spine are approached in a prone position. If the patient cannot lie in a prone position, a lateral decubitus position may be used. The supine position is preferred for cervical vertebral body biopsy. Tilting the head away from the side of the target lesion is useful, especially for cervical body lesions. For lesions in the posterior elements of the cervical spine, biopsy should be done from a prone or lateral approach. Sometimes, the lesion may be well-visualized on MRI or PET-CT very easily but not on the $\mathrm{CT}$, which is obtained during the biopsy. Therefore, an approximate correlation based on anatomic landmarks or image fusion with the use of dedicated software should be performed to determine the location of the lesion. Prebiopsy CT, MR, or PET images are also useful to target the most representative right area of the lesion such as the non-necrotic area or the solid component at the lesion periphery. ${ }^{3}$

Limited CT sections for the area of interest may be obtained to reduce the radiation dose. Intravenous contrast material administration may be required for cervical biopsy, especially to visualize the major vessels. The shortest approach should be considered and care should be taken to avoid major vessels or neural structures along the path. 


\section{Anesthesia}

At our institute, the majority of the bone biopsies are performed under local anesthesia. General anesthesia is reserved for patients in the pediatric age group (under 18 years) or for lesions in a critical location such as those in cervical spinal lesions, especially C1 or C2 vertebrae, where the slight movement of the patient can lead to disastrous complications. Patients who cannot tolerate pain or are uncooperative would benefit from general anesthesia. Fasting duration for local anesthesia is 3 to 4 hours; for sedation, it is 6 hours, and for general anesthesia, it is 8 hours. Intravenous access should be secured before the procedure. Prophylactic antibiotics are not required. ${ }^{16}$ The procedure should be performed under sterile precautions. Once the needle entry site is identified, the skin should be prepared with cleaning agents such as chlorhexidine, alcohol, or betadine. The skin, subcutaneous layers, muscles, and periosteum are then infiltrated with a local anesthetic using a 22-gauge needle. The position of the needle is checked on the CT scan. If the needle tip is in the desired location, the local anesthetic drug is injected until the periosteum. ${ }^{17,18}$ For bone puncture, we use the bone biopsy needle (Murphy's needle), either of $11 \mathrm{G}$ or $13 \mathrm{G}$ needle is used and inserted safely under CT guidance. Fluoroscopy can be used in conjunction with $\mathrm{CT}$, if available, whenever drilling is required for the sclerotic bone lesions.

4. Biopsy Technique and Needle Selection

Various types of needles are available for sampling of the tissues, ${ }^{19}$ such as needles for fine-needle aspiration (FNA), automatic/semiautomatic core biopsy needles, and the trephine needle system for bone biopsy. A combination of needles can be used, depending on the nature of the lesions.

\section{Needles for FNA}

These needles used for cytology are 20 to $22 \mathrm{G}$ needles with a beveled tip and used for cutting the tissues..$^{20}$ The needle is inserted into the lesion and then stylet is withdrawn. With the help of negative suction, the needle is moved to and fro ( 15-30 times) in the lesion. The collected material is spread on a slide and fixed with formalin or air-dried. FNA needles have the advantage of obtaining the tissue sample with a minimum risk of complications. However, it is usually reserved for cases with a suspected tumor, recurrence, or aspiration of fluid collection. The main disadvantage of FNA over core needle biopsy is that FNA shows only cytological features of the lesion and not the tissue architecture. ${ }^{21}$

\section{Automatic/Semiautomatic Core Biopsy Needles-(-Fig. 2)}

These are used for lesions that are easy to penetrate, such as lytic bone lesions or lesions with a soft-tissue component. These are available in automatic or semiautomatic or manual variants and are spring-driven devices with a cutting edge on one side. The coaxial needle system is preferred at our institute, which has a Trocar needle with diamond-shaped tip and an outer cannula. The coaxial biopsy needle system is preferred due to advantages such as obtaining a nonfragmented specimen, multiple cores with a single-needle pass, decreased procedure time, and minimizing the risk of complications such as bleeding. ${ }^{22}$ Cores obtained are used for
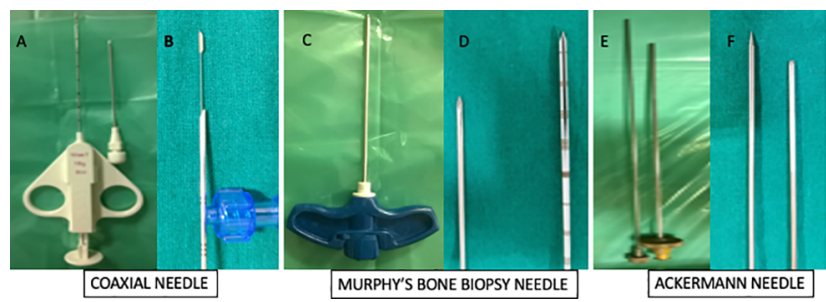

Fig. 2 (A, B). Semiautomatic core biopsy needles-(A). Coaxial needle with trocar and needle. (B). Cutting edge of needle. (C, D). Murphy's bone biopsy needle-(C). Murphy's bone biopsy needle. (D). Diamond edge trocar and outer cannula with diamond tip. (E, F). Ackerman needle-(E). Ackermann needle. (F). Outer cannula with serrated margins.

cytology, histopathology, molecular analysis, and microbiological analysis. ${ }^{23}$

\section{Bone Biopsy Needles-(-Fig. 2)}

The Murphy's bone biopsy needle (Cook Medical, Bloomington, IN) used in our institute is a large-bore needle with a diamond cutting edge on the inner trocar and serrated tip on the outer cannula. The cannula and trocar fit into each other snugly with an interlocking handle. These needles are used to obtain a bone specimen for histopathology, molecular analysis, and microbiological analysis. Murphy's bone biopsy needle (Cook Medical, Bloomington, IN) is used as a coaxial system to obtain tissue samples using Ackerman needle (Cook Medical, Bloomington, IN) as the preferred needle. Using the bone biopsy needle requires special skill and a good amount of practice. This needle needs to be drilled in the bone in a clockwise and anticlockwise rotatory action direction till the starting of the lesion is reached. The inner stylet is removed, the Ackermann needle is introduced into the lesion in a similar fashion to trap the tissue within the cannula, and the cannula is removed at one go. The bone core entrapped within the Ackermann cannula is pushed out using the inner stylet and the specimen obtained is sent for analysis.

Accuracy of the obtained sample is higher for neoplastic lesions compared with benign lesions like infections and inflammations. ${ }^{24}$ The yield of the biopsy depends on the selection of a coaxial needle system, depending on the type of lesion (soft tissue, lytic, sclerotic or mixed), location of the lesion (vertebra, intervertebral disc, paraspinal soft tissues), and method of the specimen acquisition. ${ }^{25-27}$ For lytic lesions or lesions with soft-tissue component, automatic/semiautomatic core needle is used. The combination of a bone biopsy needle along with core biopsy needle is useful when the intact cortex and the lytic lesion is present. The intact cortex of the bone can be drilled with the bone biopsy needle and then the core biopsy needle can be advanced into the lytic component ${ }^{28}$ (- Table 1). Larger-core bone biopsy (Murphy's or Ackerman needle) is preferred over needle aspiration needle for sclerotic lesions, since larger size specimen will result in a higher diagnostic accuracy. The Ackerman needle has the advantage of a coaxial system to obtain multiple cores, but the main disadvantage of this needle is that it causes sample size crushing artifact, leading to inconclusive 
Table 1 Needle used in different types of lesions with advantages of each

\begin{tabular}{|l|l|l|}
\hline Lesion type & Needle required & Advantages \\
\hline $\begin{array}{l}\text { Lytic lesion/ } \\
\text { soft tissue/ } \\
\text { lytic bone } \\
\text { with soft } \\
\text { tissue }\end{array}$ & $\begin{array}{l}\text { Coaxial core } \\
\text { biopsy needle } \\
\text { (semiautomatic/ } \\
\text { automatic) }\end{array}$ & $\begin{array}{l}\text { - Easy to penetrate } \\
\text { - Intact specimen } \\
\text { - Multiple cores with } \\
\text { single path decrease } \\
\text { the procedure time } \\
\text { - Less risk of } \\
\text { complications }\end{array}$ \\
\hline $\begin{array}{l}\text { Sclerotic/ } \\
\text { mixed lytic } \\
\text { sclerotic } \\
\text { lesion }\end{array}$ & $\begin{array}{l}\text { Bone biopsy } \\
\text { needle }\end{array}$ & $\begin{array}{l}\text {-Larger specimen with } \\
\text { bigger size cores. } \\
\text {-Multiple cores with } \\
\text { the help of Ackermann } \\
\text { Needle. }\end{array}$ \\
\hline $\begin{array}{l}\text { Intact cortex } \\
\text { with lytic } \\
\text { lesion }\end{array}$ & $\begin{array}{l}\text { Combination of } \\
\text { needles (bone } \\
\text { biopsy and core } \\
\text { biopsy needle) }\end{array}$ & $\begin{array}{l}\text {-Intact cortex needs } \\
\text { to be drilled with Bone } \\
\text { biopsy and soft tissue } \\
\text { biopsied with core } \\
\text { biopsy needle. }\end{array}$ \\
\hline $\begin{array}{l}\text { Soft tissue for } \\
\text { metastasis } \\
\text { and aspiration } \\
\text { of fluid }\end{array}$ & FNA needles & $\begin{array}{l}\text {-To prove metastasis in } \\
\text { known primary } \\
\text {-Aspiration of fluid for } \\
\text { culture } \\
\text {-Less risk of } \\
\text { complications }\end{array}$ \\
\hline
\end{tabular}

Abbreviation: FNA, fine-needle aspiration.

results. No association has been found between the radiological appearance of lesions and sufficient biopsy material or biopsy success. ${ }^{29}$ Accurate route planning and proper hardware selection are the keys to biopsy success with minimal complication.

5. Approaches and technical considerations

Different approaches depending on the vertebral level

1. Cervical vertebra ${ }^{30,31}$

a. Anterolateral-cervical body from C3 to C7 (- Figs. 3, 4).

b. Posterior-for spinous process.

c. Posterolateral-large articular masses and posterior elements (-Fig. 5).

d. Open mouth (transoral)-or lesions in C1, C2 (- Fig. 6).

2. Thoracic $^{31,32}$

a. Classical transpedicular-vertebral body, pedicle ( - Fig. 7).

b. Trans costovertebral-vertebral body, intervertebral disc.

c. Paraspinal oblique/parapedicular-intervertebral $\operatorname{disc}$ (-Fig. 8).

d. Intercostal-vertebral body masses or paravertebral masses.

e. Transforaminal-vertebral body lesion (-Fig. 9).

f. Para laminar or tangential-spinous process (-Fig. 10).

3. Lumbar $^{31}$

a. Classical transpedicular-vertebral body (-Fig. 11).

b. Posterolateral.

c. Lateral.

d. Paralaminar or tangential ( - Fig. 10).

e. Parapedicular.
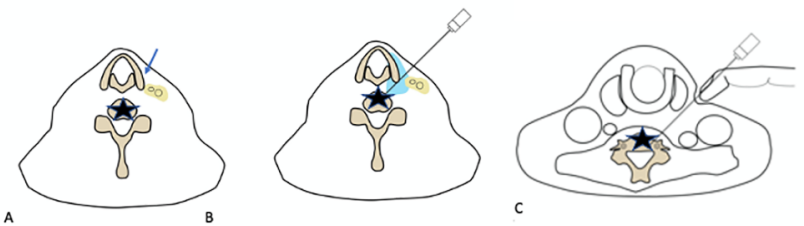

Fig. 3 Schematic images depicting the various methods of displacement of vital structure around cervical vertebral level. (A). Lesion (star) in vertebral body. Anterior or anterolateral approach is not possible as thyroid is situated anterior (blue arrow), and carotid vessels (yellow) are placed just adjacent to it. (B). Hydrodissection done with saline (blue) -displacement of carotid vessels laterally and good space for needle placement. (C). Displacement of the carotid vessels lateral with the help of finger.

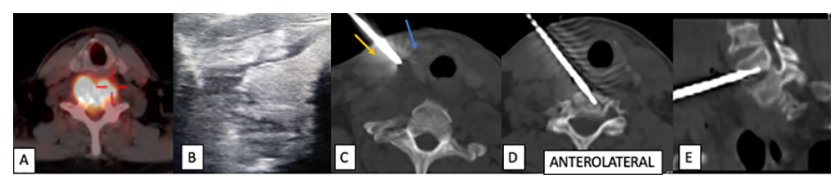

Fig. 4 A 57-year-old male patient known case of squamous cell carcinoma of the right true cord. (A). PET-CT shows solitary area of hypermetabolism at C6-C7 level. (B). Hydrodissection was done to displace thyroid gland (blue arrow) and carotid artery (yellow arrow) with spinal needle. (C). Murphy's bone biopsy (11G) needle was inserted between thyroid gland and carotid artery. (D, E). Bone biopsy was taken from C6 vertebral body and C6-C7 intervertebral discs space. A histopathology reveals, inflammatory changes and there was no evidence of malignancy.

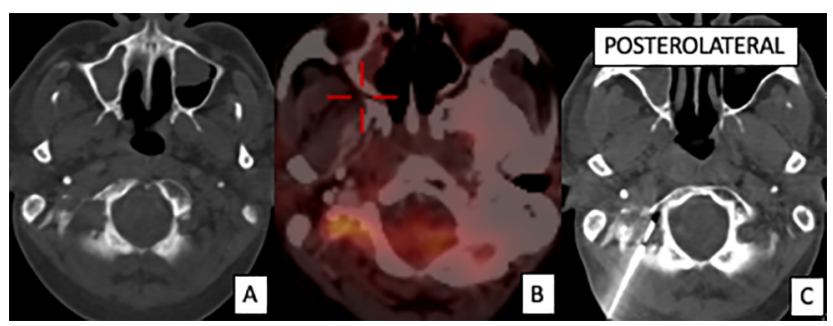

Fig. 5 A 50-year-old male with known case of nasopharynx carcinoma with hypermetabolic lesion in the right occipital condyle on PET-CT (A, B). Needle placed from posterior-medial approach directed away from major vessels and spinal cord (C). Histopathological report reveals inflammatory/infective in nature without malignancy.

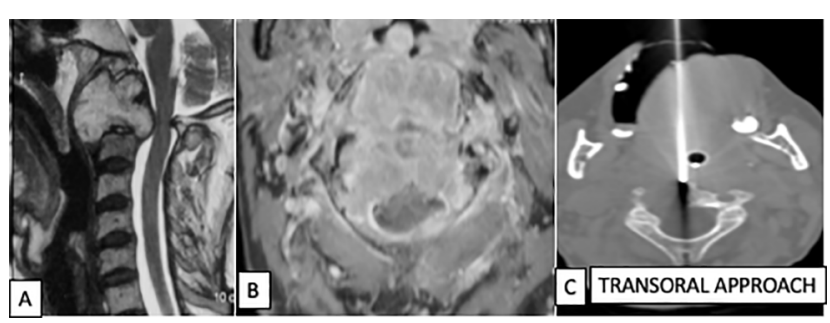

Fig. 6 A 58-yearold female with neck pain. (A, B) MRI shows C1-C2 vertebra soft-tissue lesion with complete destruction of vertebral body, which is indenting on the posterior epidural space; however, no cord signal change or compression is seen. (C) CT-guided transoral biopsy of the soft tissue was done with trans nasal intubation. Postbiopsy histopathology reveals metastasis from differentiated thyroid carcinoma. 


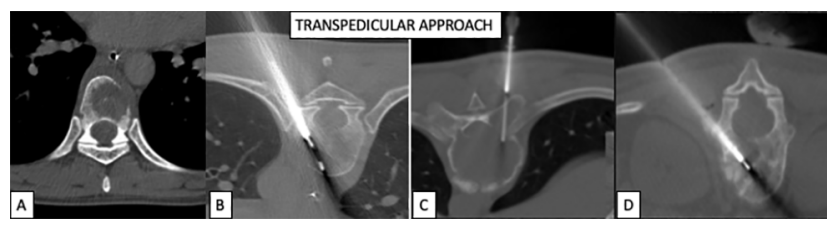

Fig. 7 A 32-year-old female known case of hypopharynx carcinoma and synchronous papillary thyroid carcinoma posttreatment. Now complains of back pain. (A) CECT shows lytic destructive lesion in the D8 vertebral body. (B) Transpedicular approach was taken with Murphy's bone biopsy needle and cutting edge core biopsy needle was used at the lytic area. Histopathogically, it revealed metastatic squamous cell carcinoma from hypopharynx. (C) A 55-year-old female with lytic destructive lesion involving the vertebral body and pedicle. CT-guided biopsy was done in prone position with cutting edge core biopsy needle placed in the lytic destructive lesion, which revealed metastasis from breast carcinoma. (D) A 60-year-old male had undergone CT-guided bone biopsy through transpedicular approach in mixed lytic sclerotic lesion with Murphy's bone biopsy needle and Ackermann needle, which revealed metastasis from prostatic carcinoma.

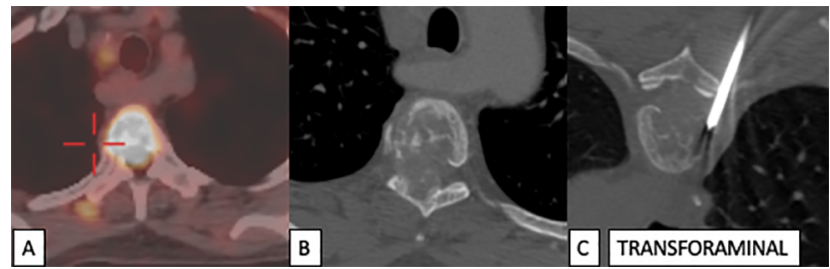

Fig. 9 A 58-year-old male who had back pain and bilateral lower limb weakness and was evaluated for same. (A, B) PET-CT reveals lytic lesion at D5 vertebral body with associated soft tissue and extension into the intervertebral foramina and spinal canal with displacement of the cord and signal changes. PET image shows FDG avid lesion. (C) Biopsy is done via posterior approach through transforaminal approach. The histopathological examination revealed medullary carcinoma of thyroid.

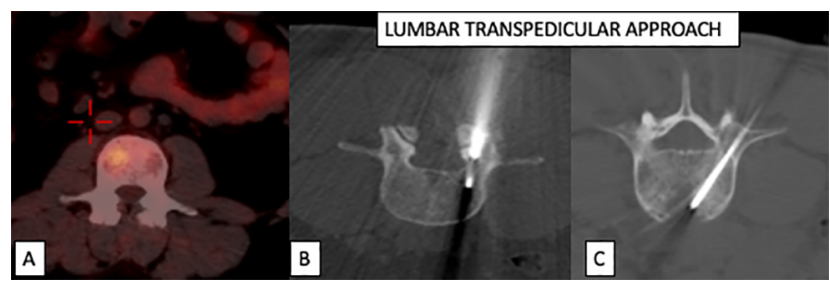

Fig. 11 A 37-year-old male complains of low back pain. (A, B) PET-CT shows FDG avid lesion at $\mathrm{L} 4$ vertebral body; however, no corresponding changes are noted on CT scan. CT-guided biopsy done from PET avid area with Murphy's bone biopsy needle and Ackermann needle via transpedicular approach, which was confirmed to be lymphoma on histology. (C) A 53-year-old male patient; CT scan shows anteriorly placed lytic lesion involving the vertebral body is approached through transpedicular route, which revealed metastasis from lung primary.

\section{Sacral.}

a. Anterior-presacral region.

b. Posterior ( - Fig. 12).

c. Posterolateral (-Fig. 12).

d. Transsacral.

\section{Cervical vertebra ( - Fig. 13 a).}

Anterolateral and posterolateral approaches are commonly used for cervical vertebral bone biopsies from C3-C7,

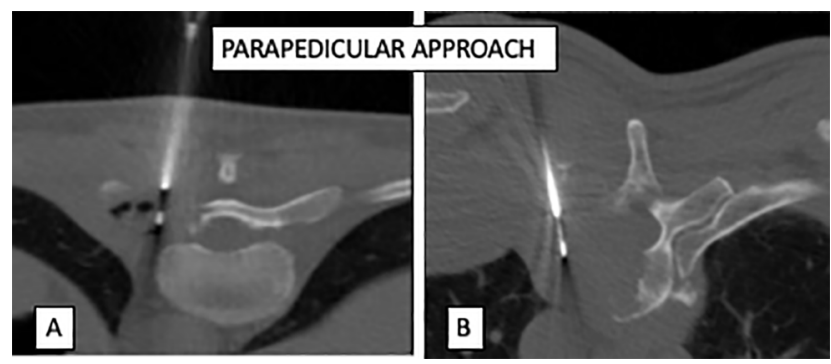

Fig. 8 CT scan shows lytic destructive lesion with soft tissue involving the transverse process and lamina (A) CT-guided biopsy done with core biopsy needle via para pedicular approach. (B) CT-guided biopsy done via parapedicular route for lytic destructive lesion with soft tissue along the vertebral body.

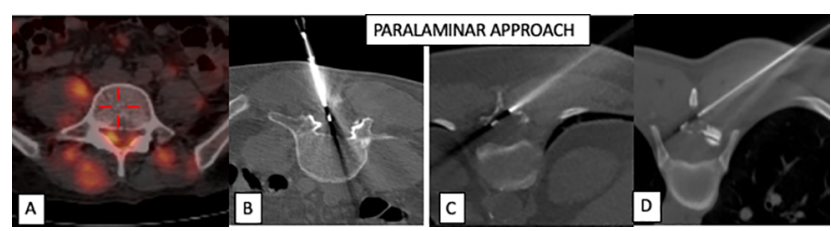

Fig. 10 A 52-year-old seropositive male, having low back pain since 1 month. (A) PET-CT reveals destruction of the lamina with epidural soft tissue at the L5 level. (B) CT-guided biopsy was done via para laminar approach in prone approach from the peripheral aspect. Histopathological examination revealed diffuse large B cell lymphoma. (C) Epidural soft tissue around the thoracic vertebra was done via paralaminar approach. (D) CT-guided biopsy of lytic destructive lesion of the spinous process of D10 done via paralaminar approach.

depending on the site of the lesion. When using the anterolateral approach, one must avoid the major vessels, that is, carotid arteries and jugular vein in the carotid space, while esophagus, trachea and pharynx in the midline. The major vessels and sternocleidomastoid muscle are retracted laterally and the needle is introduced between the airway and carotid vessels to the vertebra. Another approach is hydrodissection (instilling normal saline/dextrose to displace organ and/or vessel when they are close to each other, so as to facilitates a smooth pathway till the lesion when no safe route is possible) between the major vessels and thyroid gland to reach the lesion in the cervical vertebral body. An open mouth or transoral approach is used for lesions in the odontoid process or C1-C2 vertebra. ${ }^{30,31}$ If the anterolateral or posterolateral approach is used, the patient's head should be tilted on one side to minimize movement of the patient. The posterior approach is used for the spinous process lesion, taking care of the spinal cord, while the posterolateral approach for lesions of the lateral masses or posterior elements. The needle trajectory should be directed away from the major vessels and spinal cord.

\section{Thoracic vertebra ( - Fig. 13 b)}

The biopsy of a thoracic vertebra is performed using CT and/or fluoroscopic guidance. While transpedicular, transcostovertebral, and foraminal approaches are used to biopsy body of the thoracic vertebra, transcostovertebral and paraspinal oblique pathways are used to sample the intervertebral disc. For the lesions located in the paraspinal or 


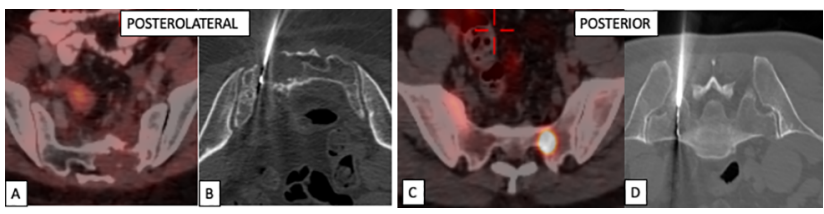

Fig. 12 A 15-year-old female known case of synovial sarcoma postradiation therapy; now, she complains of low back pain. (A) PET scan reveals low grade FDG avid lesion in the left sacral ala. (B) CT-guided biopsy done with cutting edge core biopsy needle in view of lytic lesion with soft-tissue component via posterior lateral approach, which on histopathology reveals recurrence. (C) PET-CT shows FDG avid lesion in the left sacral ala. (D) CT-guided biopsy done by Murphy's bone biopsy needle and cutting-edge needle via posterior approach which turned shows diffuse large B cell Lymphoma on histology.

lateral thoracic vertebral regions, costovertebral or intercostal approach can be used.

While using a transpedicular biopsy, fluoroscopy allows real-time imaging of the needle passage. The transpedicular approach is the safest approach for vertebral body biopsy. ${ }^{33,34}$ The long transverse process may limit the accessibility of thoracic vertebral lesions; hence, the posterolateral or parapedicular or intercostovertebral approaches are preferred. ${ }^{35,36}$ The limitations of the transpedicular approach include are difficult penetration of the bony cortex, the possibility of injury to the medial and inferior walls of the pedicle, spinal canal structures, nerve roots and inability to reach the intervertebral disc. ${ }^{37}$ In such situations, transforaminal or transcostovertebral discal biopsy becomes advantageous. In the transcostovertebral approach, the needle enters between the tubercle of the rib and the transverse process and requires drilling through the facet joint. This approach keeps the needle away from the pleura or lung laterally and exiting nerve roots and pedicle medially.

A paralaminar or tangential approach is used for the lesions involving the neural arch structures. The advantage is the direction of needle trajectory being away from the neural structures. This approach depends on the location lesion and should be appropriately planned for each patient.

\section{Lumbar vertebra (-Fig. 13 c)}

The transpedicular approach is commonly used for biopsy for vertebral body and pedicular lesions biopsy. This approach is similar to that for thoracic vertebra. The lateral approach in lateral decubitus can be used when the patient is unable to lie down in a prone position, and this can be used for vertebral body, disc and paraspinal soft tissues. ${ }^{38}$ The approach to biopsy should be such that the skin and the entire biopsy tract can be easily excised during the surgical resection of the tumor and hence the skin entry should be at the site of the potential surgical incision.

\section{Sacral Vertebra}

CT-guided biopsy of the sacral lesions is better as compared with fluoroscopic-guided, because of the complex structural anatomy of the sacrum.

a. Presacral and anterior vertebral lesion-Anterior approach is preferred, but at times this anterior approach may be difficult, because of bowel loops or major vessels in the
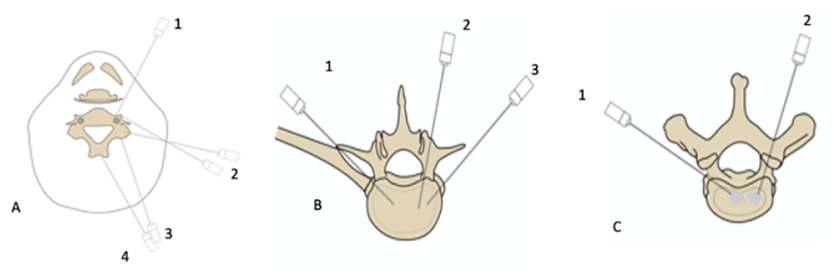

Fig. 13 Various approaches of vertebral biopsy in cervical (A), thoracic (B) and lumbar vertebra (C). Cervical vertebra (A) -needle positions 1) Anterolateral, 2) Lateral, 3) Posterolateral, 4) Posteromedial. Thoracic vertebra (B) -needle positions 1) Costovertebral 2) Transpedicular 3) Paraspinal. Lumbar vertebra (C)-needle positions 1) Posterolateral 2) Transpedicular.

path. A longer length of the needle may help in such situations. Another method is the transsacral approach from the posterior aspect, which uses a combination of the needles. A bone biopsy needle is used to drill the bony cortex from posterior to the anterior surface, and after removal of the inner stylet, the core biopsy needle is used to obtain a sample from the soft tissue.

b. Sacral ala lesions-Posterior or posterolateral approaches may be used.

c. Spinous process-Posterior or posterolateral approaches may be used.

\section{Postprocedure care:}

If the procedure is performed under local anesthesia, the patient should be monitored in the recovery room. The vitals and biopsy site should be checked every 15 minutes for 1 hour, and then every 30 minutes for 2 hours for any complications. If the procedure is performed under general anesthesia or deep sedation, monitoring should continue till the patient is weaned off the effect of anesthetic drugs. If a posterior approach is used then the patient should lie in a supine position during the recovery. Antiplatelet drugs such as clopidogrel can be restarted after 6 hours of the procedure, if using $75 \mathrm{mg}$ dose, while others such as LMWH can be restarted after 12 hours and direct oral anticoagulants (DOACs) after 24 hours. ${ }^{39}$ A chest radiograph may be performed to rule out pneumothorax following thoracic vertebral biopsies if the procedure is done under fluoroscopic guidance. Patients may be given analgesics for pain relief.

\section{Outcomes}

The diagnostic accuracy of the CT-guided biopsy is in the range of 70 to $93 \%$ in the published literature. ${ }^{40-42}$ The accuracy is approximately $90 \%$ for malignancies and metastases as compared with around $80 \%$ for benign tumors. Also, primary malignancies have a lower diagnostic yield as compared with metastases. Rimondi et al showed that the diagnostic accuracy of the biopsies is lower in the cervical region as compared with lumbar or thoracic regions, due to the small size of the lesions and difficult access. ${ }^{24}$ Since the size of the cervical vertebra body is small, there are technical difficulties, and nondiagnostic biopsies are more common. ${ }^{33}$ Cystic, sclerotic, and necrotic lesions have lower diagnostic yields. ${ }^{5}$ In a study by Yang et al, lytic (88\%) or mixed (84\%) lesions showed the 
diagnostic yield as compared with sclerotic (67\%) or isodense (61\%) lesions. ${ }^{43}$ Sclerotic lesions have low cellularity and reactive new bone formation, which may require the use of the drill, leading to crushing artifacts and decalcification prior to processing. The diagnostic yield of lesions bigger than $2 \mathrm{~cm}$ is higher (84\%) compared with smaller lesions (52\%). ${ }^{43} \mathrm{~A}$ repeat biopsy may be required when histopathology results are nondiagnostic. However, this should be preceded by an imaging review for the possibility of the lesion being benign or inflammatory.

\section{Complications}

A CT-guided percutaneous biopsy is safer compared with open surgical biopsy. Lower rates of complications and shorter hospital stays make it the procedure of the choice. Although radiation can be a problem with CT guidance, the benefits outweigh the risks. According to a metanalysis, the complications of percutaneous bone biopsy are in the range of 0 to $10 \%{ }^{44}$

Acute complications may occur during or immediately after the procedure. One of the common acute complications includes bleeding due to vascular injury. Arterial bleeding is life-threatening and requires immediate interventions. Venous bleeding presents late in the form of paravertebral ooze. ${ }^{9}$ When a hypervascular tumor, arising from the pedicle or posterior vertebral body cortex and extending into the central canal, bleeds after the biopsy, it may result in cord compression. Other complications include nerve roots injury, leading to paraplegia and pneumothorax during a thoracic vertebral biopsy. Late complications include infection, tumor spread, and vertebral fracture. ${ }^{25}$

\section{Limitations}

The two main limitations of vertebral biopsy include sample crushing and insufficient material, leading to inconclusive results. Most of the rebiopsies are seen in sclerotic, cystic, or necrotic lesions with low yield rates despite repeated biopsies. ${ }^{7}$ Another reason for low yield is the presence of a benign lesion as opposed to a malignant lesion, or when the patient is on broad-spectrum antibiotics prior to sampling of suspected infective focus in the bone. ${ }^{45}$

\section{Conclusions}

CT-guided percutaneous biopsy of the spine is a safe and effective procedure. CT helps in identifying and targeting the lesions accurately and minimizing the complications. Sound radiological knowledge, knowledge of the hardware, and assessment of lesion anatomy on prior images are important. Anatomical landmarks are important to identify the of critical structures and planning the appropriate approach.

\section{Conflict of Interest}

None declared.

\section{Acknowledgment}

Mr. Nilesh Ganthade for schematic diagrams.

\section{References}

1 Desai SS. Early diagnosis of spinal tuberculosis by MRI. J Bone Joint Surg Br 1994;76(6):863-869

2 Takenaka D, Ohno Y, Matsumoto K, et al. Detection of bone metastases in non-small cell lung cancer patients: comparison of whole-body diffusion-weighted imaging (DWI), whole-body MR imaging without and with DWI, whole-body FDG-PET/CT, and bone scintigraphy. J Magn Reson Imaging 2009;30(2):298-308

3 Bickels J, Jelinek JS, Shmookler BM, Neff RS, Malawer MM. Biopsy of musculoskeletal tumors. Current concepts. Clin Orthop Relat Res 1999;368(368):212-219

4 Tan SB, Kozak JAMM, Mawad ME. The limitations of magnetic resonance imaging in the diagnosis of pathologic vertebral fractures. Spine 1991;16(8):919-923

5 Lis E, Bilsky MH, Pisinski L, et al. Percutaneous CT-guided biopsy of osseous lesion of the spine in patients with known or suspected malignancy. AJNR Am J Neuroradiol 2004;25(9):1583-1588

6 Chang CY, Huang AJ, Bredella MA, et al. Percutaneous CT-guided needle biopsies of musculoskeletal tumors: a 5-year analysis of non-diagnostic biopsies. Skeletal Radiol 2015;44(12):1795-1803

$7 \mathrm{Wu}$ JS, Goldsmith JD, Horwich PJ, Shetty SK, Hochman MG. Bone and soft-tissue lesions: what factors affect diagnostic yield of image-guided core-needle biopsy? Radiology 2008;248(3):962-970

8 Heyer CM, Al-Hadari A, Mueller KM, Stachon A, Nicolas V. Effectiveness of CT-guided percutaneous biopsies of the spine: an analysis of 202 examinations. Acad Radiol 2008;15(7):901-911

9 Dupuy DE, Rosenberg AE, Punyaratabandhu T, Tan MHH, Mankin HJ. Accuracy of CT-guided needle biopsy of musculoskeletal neoplasms. AJR Am J Roentgenol 1998;171(3):759-762

10 Ebraheim NA, Rollins JRJ Jr, Xu R, Yeasting RA. Projection of the lumbar pedicle and its morphometric analysis. Spine 1996;21(11):1296-1300

11 Ebraheim NA, Xu R, Ahmad M, Yeasting RA. Projection of the thoracic pedicle and its morphometric analysis. Spine 1997;22(3):233-238

12 Mills MK, Shah LM. Imaging of the perivertebral space. Radiol Clin North Am 2015;53(1):163-180

13 Patel IJ, Davidson JC, Nikolic B, et al; Standards of Practice Committee, with Cardiovascular and Interventional Radiological Society of Europe(CIRSE)Endorsement. Consensus guidelines for periprocedural management of coagulation status and hemostasis risk in percutaneous image-guided interventions. J Vasc Interv Radiol 2012;23(6):727-736

14 Veltri A, Bargellini I, Giorgi L, Alexandre P, Silva M, Okan A. CIRSE Guidelines on Percutaneous Needle Biopsy (PNB) Cardiovasc Intervent Radiol 2017;40(10):1501-1513

15 Gupta S, Wallace MJ, Cardella JF, Kundu S, Miller DL, Rose SC; Society of Interventional Radiology Standards of Practice Committee. Quality improvement guidelines for percutaneous needle biopsy. J Vasc Interv Radiol 2010;21(7):969-975

16 Lee MJ, Fanelli F, Haage P. Hausegger K, Van Lienden KP. Patient safety in interventional radiology: a CIRSE IR checklist. Cardiovasc Intervent Radiol 2012;35(2):244-246

17 Ghelman B. Biopsies of the musculoskeletal system. Radiol Clin North Am 1998;36(3):567-580

18 Hadjipavlou AG, Kontakis GM, Gaitanis JN, Katonis PG, Lander P, Crow WN. Effectiveness and pitfalls of percutaneous transpedicle biopsy of the spine. Clin Orthop Relat Res 2003; (411):54-60

19 Davis TM, Spinal biopsy techniques. In: McGraw JK, ed. Interventional Radiology of the Spine. Totowa, NJ: Humana Press Inc; 2004 181-96 
20 Haaga JR, LiPuma JP, Bryan PJ, Balsara VJ, Cohen AM. Clinical comparison of small-and large-caliber cutting needles for biopsy. Radiology 1983;146(3):665-667

21 Domanski HA, Akerman M, Carlén B, et al. Core-needle biopsy performed by the cytopathologist: a technique to complement fine-needle aspiration of soft tissue and bone lesions. Cancer 2005;105(4):229-239

22 Yaffe D, Greenberg G, Leitner J, Gipstein R, Shapiro M, Bachar GN. CT-guided percutaneous biopsy of thoracic and lumbar spine: A new coaxial technique. AJNR Am J Neuroradiol 2003;24(10):2111-2113

23 Joshi A, Magar SR, Chand P. Panth R, Khatri Chhetri BR. Tru-cut biopsy as the initial method of tissue diagnosis in bone tumors with soft tissue extension. Indian J Orthop 2013;47(2):195-199

24 Rimondi E, Staals EL, Errani C, et al. Percutaneous CT-guided biopsy of the spine: results of 430 biopsies. Eur Spine J 2008;17(7):975-981

25 Olscamp A, Rollins J, Tao SS, Ebraheim NA. Complications of CT-guided biopsy of the spine and sacrum. Orthopedics 1997;20(12):1149-1152

26 Kattapuram V, Rosenthal I. Review article percutaneous biopsy of skeletal lesions. AJR 1991;157:934-942

27 Freiberger H. Closed biopsy: skeletal review needle. AJR Am J Roentgenol 1983;140(1):113-115

28 Garg V, Kosmas C, Josan ES, et al. Computed tomography-guided percutaneous biopsy for vertebral neoplasms: a department's experience and hybrid biopsy technique to improve yield. Neurosurg Focus 2016;41(2):E17

29 Gul SB, Polat AV, Bekci T, Selcuk MB. Accuracy of percutaneous CT-guided spine biopsy and determinants of biopsy success. J Belg Soc Radiol 2016;100(1):62

30 Ottolenghi CE, Schajowicz F, Deschant FA. Aspiration biopsy of the cervical spine. Technique and results in thiry-four cases. J Bone Joint Surg Am 1964;46:715-733

31 Geremia G, Joglekar S. Percutaneous needle biopsy of the spine. Neuroimaging Clin N Am 2000;10(3):503-533

32 Stringham DR, Hadjipavlou A, Dzioba RBLP, Lander P. Percutaneous transpedicular biopsy of the spine. Spine 1994;19(17):1985-1991

33 McGraw JK, Spinal Biopsy Techniques. Totowa, NJ: Humana Press Inc; 2004 181-196
34 Pierot L, Boulin A. Percutaneous biopsy of the thoracic and lumbar spine: transpedicular approach under fluoroscopic guidance. AJNR Am J Neuroradiol 1999;20(1):23-25

35 Renfrew DL, Whitten CG, Wiese JA, el-Khoury GY, Harris KG. CT-guided percutaneous transpedicular biopsy of the spine. Radiology 1991;180(2):574-576

36 Ward JC, Jeanneret B, Oehlschlegel C, Magerl F. The value of percutaneous transpedicular vertebral bone biopsies for histologic examination. Results of an experimental histopathologic study comparing two biopsy needles. Spine 1996;21(21):2484-2490

37 Aribas BK, Dingil G, Dogan K, Sahin G, Pak I, Ardic F. Factors in sample volume and quality of CT-guided vertebral biopsy: location and needle trajectory. Turk Neurosurg 2010;20(1):21-26

38 Garcés J, Hidalgo G. Lateral access for CT-guided percutaneous biopsy of the lumbar spine. AJR Am J Roentgenol 2000;174(2):425-426

39 Patel IJ, Rahim S, Davidson JC, et al. Society of Interventional Radiology Consensus Guidelines for the Periprocedural Management of Thrombotic and Bleeding Risk in Patients Undergoing Percutaneous Image-Guided Interventions-Part II: Recommendations: Endorsed by the Canadian Association for Interventional Radiology and the Cardiovascular and Interventional Radiological Society of Europe. J Vasc Interv Radiol 2019;30(8):1168-1184.e1

40 Hau A, Kim I, Kattapuram S, et al. Accuracy of CT-guided biopsies in 359 patients with musculoskeletal lesions. Skeletal Radiol 2002;31(6):349-353

41 Yang YJDT, Damron TA. Comparison of needle core biopsy and fine-needle aspiration for diagnostic accuracy in musculoskeletal lesions. Arch Pathol Lab Med 2004;128(7):759-764

42 Puri A, Shingade VU, Agarwal MG, et al. CT-guided percutaneous core needle biopsy in deep seated musculoskeletal lesions: a prospective study of 128 cases. Skeletal Radiol 2006;35(3):138-143

43 Yang SY, Oh E, Kwon JW, Kim HS. Percutaneous image-guided spinal lesion biopsies: Factors affecting higher diagnostic yield. AJR Am J Roentgenol 2018;211(5):1068-1074

44 Nourbakhsh A, Grady JJ, Garges KJ. Percutaneous spine biopsy: a meta-analysis. J Bone Joint Surg Am 2008;90(8):1722-1725

45 Czervionke LFFD. Percutaneous spine biopsy. Image Guided Spine Interv 2003;xx:141-187 